\title{
Fatty Acid-Induced Lipotoxicity in Pancreatic Beta-Cells During Development of Type 2 Diabetes
}

\author{
Yoon S. Oh ${ }^{1 *}$, Gong D. Bae ${ }^{2}$, Dong J. Baek ${ }^{3}$, Eun-Young Park ${ }^{3}$ and Hee-Sook Jun ${ }^{2,4,5}$ \\ ${ }^{1}$ Department of Food and Nutrition, Eulji University, Seongnam, South Korea, ${ }^{2}$ Department of Molecular Medicine, Lee Gil Ya \\ Cancer and Diabetes Institute, Gachon University, Incheon, South Korea, ${ }^{3}$ College of Pharmacy and Natural Medicine \\ Research Institute, Mokpo National University, Jeonnam, South Korea, ${ }^{4}$ Gachon Institute of Pharmaceutical Science, College \\ of Pharmacy, Gachon University, Incheon, South Korea, ${ }^{5}$ Gachon University Gil Medical Center, Gachon Medical and \\ Convergence Institute, Incheon, South Korea
}

OPEN ACCESS

Edited by:

Anca Dana Dobrian

Eastern Virginia Medical School,

United States

Reviewed by:

Yukihiro Fujita,

Asahikawa Medical University, Japan

Angela Lombardi,

Albert Einstein College of Medicine,

United States

*Correspondence:

Yoon S. Oh

ysoh@eulji.ac.kr

Specialty section:

This article was submitted to

Diabetes,

a section of the journal

Frontiers in Endocrinology

Received: 07 March 2018

Accepted: 25 June 2018

Published: 16 July 2018

Citation:

Oh YS, Bae GD, Baek DJ, Park E-Y

and Jun H-S (2018) Fatty

Acid-Induced Lipotoxicity in

Pancreatic Beta-Cells During

Development of Type 2 Diabetes.

Front. Endocrinol. 9:384.

doi: 10.3389/fendo.2018.00384
Type 2 diabetes is caused by chronic insulin resistance and progressive decline in beta-cell function. Optimal beta-cell function and mass is essential for glucose homeostasis and beta-cell impairment leads to the development of diabetes. Elevated levels of circulating fatty acids (FAs) and disturbances in lipid metabolism regulation are associated with obesity, and they are major factors influencing the increase in the incidence of type 2 diabetes. Chronic free FA (FFA) treatment induces insulin resistance and beta-cell dysfunction; therefore, reduction of elevated plasma FFA levels might be an important therapeutic target in obesity and type 2 diabetes. Lipid signals via receptors, and intracellular mechanisms are involved in FFA-induced apoptosis. In this paper, we discuss lipid actions in beta cells, including effects on metabolic pathways and stress responses, to help further understand the molecular mechanisms of lipotoxicity-induced type 2 diabetes.

Keywords: fatty acid, beta-cell, lipotoxicity, insulin secretion, type 2 diabetes

\section{INTRODUCTION}

Type 2 diabetes is a heterogeneous syndrome that is related to both defective insulin secretion and peripheral insulin resistance. Beta cells are the major organs for secreting insulin; hence, it is important to maintain an adequate beta-cell mass in response to various changes. Free fatty acids (FFAs) are nutrients involved in the energy metabolism of most organisms and are known to regulate beta-cell equilibrium. There is some evidence that elevated fasting and postprandial FFA concentrations increase the risk of developing type 2 diabetes and obesity $(1,2)$. When insulin resistance occurs, elevated FFA levels acutely increase beta-cell mass and insulin secretion to compensate for insulin insensitivity. However, chronic increases of plasma FFA concentrations result in disturbances in lipid metabolism regulation, which contribute to decreased beta-cell function and viability (lipotoxicity), and consequently induce type 2 diabetes (3) (Figure 1).

Prospective studies with subjects at risk for type 2 diabetes demonstrate that development of abdominal obesity is correlated with loss of beta-cell function (4). Lipotoxicity caused by chronic dyslipidemia impairs the metabolism of lipids in a detrimental cycle, leading to further beta-cell damage (5). In PROMISE cohort study during 6 years, total FFA concentration, but not specific fatty acid composition, was a strong predictor of beta- cell function (6). However, FA composition is one of the critical factors in the induction of lipotoxicity in beta-cells and type 2 diabetes (7).

Fatty acids are classified by carbon chain length. Short-chain fatty acids (SCFA) contain fewer than 6 carbons, medium-chain fatty acids (MCFAs) have 6-12 carbons, and long-chain 


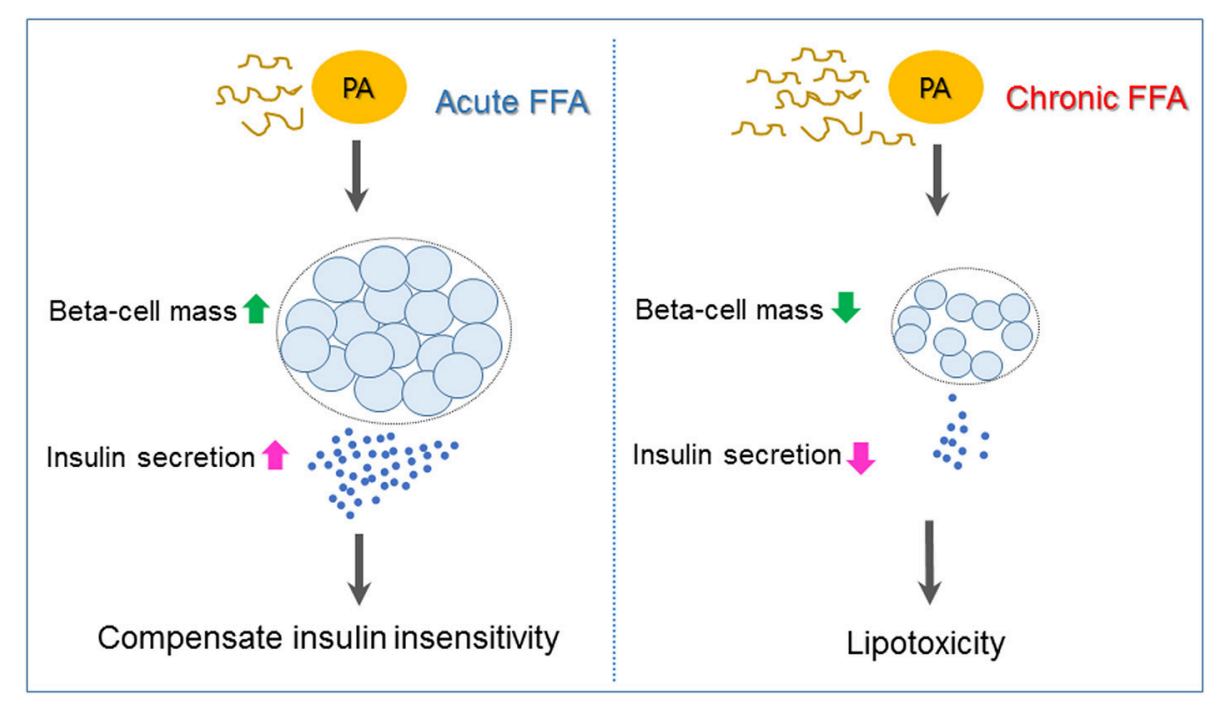

FIGURE 1 | Mechanisms underlying pancreatic beta-cell failure induced by lipotoxicity. When insulin resistance occurs, elevated free fatty acid (FFA) such as palmiate (PA) acutely increases beta-cell mass and insulin secretion to compensate for insulin insensitivity. Chronic increases of plasma FFA result in lipotoxicity, which contributes to beta-cell dysfunction and apoptosis and, as a consequence, induces type 2 diabetes.

fatty acids (LCFAs) contain more than 12 carbons. Moreover, according to the double bond configuration, saturated fatty acids (SFA) and unsaturated fatty acids are categorized, that can be classified as mono (MUFA) or polyunsaturated (PUFA) (8). The effects of a specific fatty acid (FA) on insulin secretion and betacell survival are related to the degree of saturation and carbon chain length of the FA. Saturated molecules with a chain length of carbon $(\mathrm{C}) 16$ or greater [palmitate $(\mathrm{C} 16: 0)$ or stearate $(\mathrm{C} 18: 0)$ ] induced cytotoxicity, whereas a reduction of the carbon chain length to $\mathrm{C} 14(\mathrm{C})$ (myristate) or C12:0 (laurate) are less toxic to beta-cells (9). But unsaturated fatty acids (both mono and poly unsaturated fatty acids) do not induce beta-cell apoptosis and this effects was chain length independent. Treatment of beta cells with an unsaturated FA, such as arachidonic acid (C20:4), increases glucose-stimulated insulin secretion (GSIS) and beta-cell proliferation (10). Docosahexaenoic acid (DHA, C22:6) and eicosapentaenoic acid (EPA, C20:5) also prevent cytokine induced cell death in pancreatic islets and enhance insulin secretion (11). Other studies demonstrated that cytokine treatment induced cell death in the wild type islets, but islets from the mfat-1 transgenic mice (containing DHA and EPA) showed resistance to cytokine induced cell death $(12,13)$. Therefore, controlled supplementation of PUFAs has been shown to decrease triglyceride and cholesterol levels and enhance insulin secretion (14).

Dietary fats, specifically unsaturated fatty acids can modulate type 2 diabetes development and among them, palmitic acid is one of the main fatty acid involved in the lipotoxicity during the type 2 diabetes progression. Prolonged exposure to palmitate (PA), an ester of the saturated palmitic acid, inhibits the secretory capacity of beta cells, impairs insulin gene expression, and increases beta-cell apoptosis (15).

It is widely reported that lipotoxicity induced by PA promotes beta-cell apoptosis, but the mechanisms are not fully described and many proposed models are still being investigated (14). This review discusses mechanisms, such as expression of receptors, synthesis of de novo ceramide, lipid droplet (LD) formation, endoplasmic reticulum (ER) stress, mitochondrial dysfunction, and autophagy, that regulate beta-cell death and dysfunction with a focus on development of type 2 diabetes.

\section{FATTY ACIDS AND LIPOTOXICITY}

Prolonged exposure of isolated islets or insulin-secreting cells to elevated FA levels is associated with inhibition of GSIS, reduction of insulin gene expression, and induction of cell death by apoptosis. Compared to untreated rat islets, rat islets cultured for 7 days in the presence of high levels of FFAs exhibit the hallmark events of apoptosis such as DNA fragmentation, increased caspase activity, ceramide formation, and expression of apoptotic genes (16). When a high-fat diet (HFD) is administrated to non-obese Goto-Kakizaki (GK) rats, beta-cell dysfunction is increased (17). Moreover, intralipid-induced impairment in beta-cell function is accelerated in obese subjects with glucose intolerance and mild hyperglycemia (18). Lipid or FFA exposure activates FFA receptors and cell stress responses including ceramide formation, LD formation, ER stress, mitochondria dysfunction, and autophagy, and these responses result in betacell damage and impaired insulin secretion (Figure 2).

\section{FFA Receptors CD36}

CD36 is an $\mathrm{N}$-linked glycosylated transmembrane protein that is also known as FA translocase (FAT). After cross the cell membrane via CD36, fatty acids are activated by fatty acyl-CoA synthetase to generate acyl-CoA which undergoes $\beta$-oxidation. Acyl-CoA also enters the glycerolipid/free fatty acid cycle or participates in sphingolipid synthesis to generate 


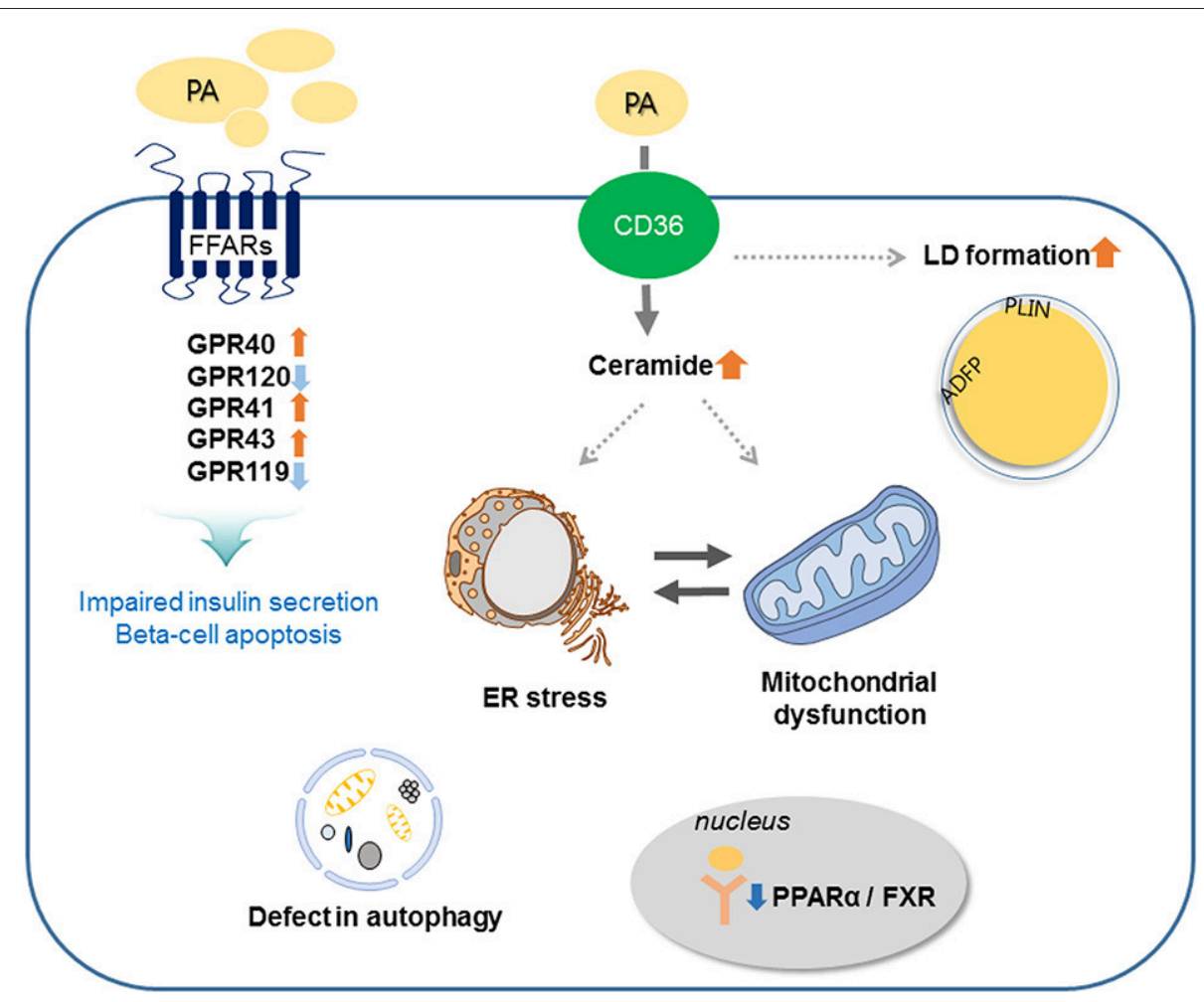

FIGURE 2 | Involved mechanisms regarding impaired insulin secretion and beta-cell apoptosis under lipotoxic condition in pancreatic beta-cells. Palmitate (PA) activates CD36 or FFA receptors (FFARs) and cell stress responses including ceramide formation, lipid droplet (LD) formation, endoplasmic reticulum (ER) stress, mitochondrial dysfunction, and autophagy. These responses result in beta-cell damage and impaired insulin secretion.

metabolites such as ceramides and sphingosine-1 phosphate (19). The binding of long chain FFA to CD36 stimulates the tyrosine phosphorylation of downstream proteins, including proinflammatory response associated with diabetes (20). CD36 is upregulated in response to high glucose in beta-cell, and upregulation of CD36 transporter in beta-cells increases uptake of FA, which are amelioration of the GSIS and impaired oxidative metabolism (21). Sulfo-N-succinimidyl derivatives have been developed as selective inhibitors for CD36, and preincubation with CD36 inhibitor prevents saturated FFA-induced apoptosis via reduced reactive oxygen species (ROS) production (22). In addition to role in FFA transport, CD36 has an important role in signal transduction through activation of non-receptor tyrosine kinases of the Src family (20). These results suggested that CD36 could be a therapeutic target for the treatment of diabetes induced by lipotoxicity.

\section{G-Protein Coupled Receptors (GPRs)}

FFAs bind to GPRs and regulate insulin secretion pathways. Four FFA receptors, FFAR1 (GPR40), FFAR2 (GPR43), FFAR3 (GPR41), and FFAR4 (GPR120), are expressed in human and rodent beta-cells, but those receptors have different chain length specificities, and the degree of saturation affects insulin secretory function (23). FFAR1 and FFAR4 are activated by mediumand long-chain FAs, while the other two receptors are activated by short-chain FAs. Among the receptors, FFAR1 and FFAR4 are the most closely related to lipotoxicity-induced beta-cell apoptosis.

FFAR1 (GPR40) is activated by medium- and long-chain FFAs [especially, ecosatrienoic acid (C20:3)] and facilitates GSIS in pancreatic beta cells $(24,25)$. Insulin secretory effect of FFAs on beta-cells was decreased by loss of FFAR1 function. Steneberg et al. demonstrated that loss of FFAR1 protects mice from obesity induced hyperinsulinemia, hyperglycemia and glucose intolerance, but overexpression of FFAR1 in beta-cell of mice leads to impaired beta-cell function and diabetes (26). PA treatment of human islets decreases insulin content and secretion, and those decreases can be prevented by treatment with FFAR1 antagonists (27). These results suggested that FFAR1 antagonists may have therapeutic benefits. However, other studies showed that upregulation of FFAR1 protects against lipotoxicity in rat insulinoma (INS-1) cells (28), while FFAR1 overexpression in islet beta cells improves GSIS and glucose tolerance in vivo (29). In human study, a single nucleotide polymorphism at the FFAR1 locus is correlated with insulin secretory dysfunction (30). FFAR1 is also expressed intestinal $\mathrm{L}$ and $\mathrm{K}$ cells, which secrete incretin hormones such as glucagon-like peptide 1 (GLP-1) and glucosedependent insulinotropic polypeptide (GIP) (31), suggested that FFAR1 regulate FFA-induced insulin secretion from betacells directly and indirectly by regulation of incretin secretion. Therefore, many pharmaceutical companies and academic 
institutes are undertaking development of FFAR1 agonists such as Tak-875, LY2881835, and AMG-837 (32). Tak-875 reduced glycemia in diabetic patients but not in normoglycemic people without diabetes and progressed to phase III clinical trials (33). However, the development was discontinued because of hepatotoxicity (34). Recently, some agonist such as P11187, LY2922470, and SHR0534 are currently in phase I clinical trials (32).

FFAR4 (GPR120) is unsaturated FFA ( $\omega-3, \omega-6$, and $\omega-9)$ and saturated FFAs with long- chain carbon sensor. Among them, two $\omega$-3 FAs, docosahexaenoic acid (DHA) and $\alpha$-linoleic acid, are the most potent and most common GPR120 agonists (35). GPR120 increases insulin release from beta cells via increases in incretin (glucagon-like peptide-1) secretion by intestinal cells (35) and exhibits an anti-apoptotic effect via activation of extracellular signal-regulated kinase (ERK) and phosphoinositide 3-kinase (PI3K)-Akt (protein kinase B) (36). FFAR4 KO mice develop glucose intolerance, and a dysfunctional variant of FFAR4 $(\mathrm{R} 279 \mathrm{H})$ is associated with obesity in humans (37). Therefore, activation of pancreatic GPR120 may mediate the anti-apoptotic effects of poly unsaturated FAs in diabetic beta cells.

FFAR2 (GPR43) and FFAR3 (GPR41) are short-chain FA [propionate (C3), butyrate $(\mathrm{C} 4)$, and valerate $(\mathrm{C} 5)$ ] receptors that mediate inhibition of insulin secretion by coupling with $G$ proteins. Genetic deletion of both receptors in beta- cells show enhanced insulin secretion and improved glucose tolerance in HFD-fed diabetic mice compared with that in controls (38). However, GPR43 and GPR41 are involved in GLP-1 secretin from intestinal L cells. They were abundantly expressed in L cells and knockout mice of these receptors exhibited reduced short chain FA-mediated GLP-1 secretion both in vitro and in vivo and results in impaired glucose tolerance (39). These results suggest that development of agonist or antagonists of GPR43 and GPR41 may be expected to be efficacious in improving insulin secretion in type 2 diabetic subjects.

Agonists for GPR119, a highly expressed beta-cell receptor for FA metabolites (lysophosphatidylcholine, oleoylethanolamine), act as insulin secretagogues. A GPR119-specific agonist, AR231453, increases insulin release in HIT-T15 cells (a hamster pancreatic beta-cell line) and rodent islets. Moreover, AR231453 treatment in diabetic KK-Ay mice improves glucose tolerance (40). N-oleoyldopamine, a lipid amide, activates GPR119, enhances insulin secretion in RIN-5F cells (a rat islet cell line), and improves glucose tolerance when administered orally to C57BL/6J mice (41).

\section{Nuclear Receptors}

Peroxisome proliferator-activated receptor alpha (PPAR- $\alpha$ ) serves as a long-chain FA sensor and regulates FA metabolism by decreasing lipid content and minimizing lipotoxicity (42). PPAR- $\alpha$ has a role in protecting beta-cells from oleate-induced dysfunction. In INS-1 cells, insulin secretory dysfunction induced by oleate is accelerated by PPAR- $\alpha$ siRNA treatment, and overexpression of PPAR- $\alpha$ stimulates insulin secretion in human islets (43).

Farnesoid X receptor (FXR), a bile acid receptor, is another key nuclear receptor regulating beta-cell function in human islet and beta-cell cell lines (44). FXR is predominantly localized in the cytosol of islets of normal mice but translocates to the nucleus under a diabetic condition. GSIS is impaired in islets of FXR KO mice, and FXR activation protects human islets from lipotoxicity and enhances insulin secretory function (44). Vmaf musculoaponeurotic fibrosarcoma oncogene homolog (Maf) A, Beta2/Neuro D1, and pancreatic and duodenal homeobox (Pdx)-1 (a master transcription factor regulating the insulin gene), and GSIS are reduced in FXR KO islets. The molecular mechanisms by which FXR activation leads to insulin secretion and protects lipotoxicity is unclear, but expression of FGF-19, a member of the FGF family was increased by treatment with FXR agonist and increased FGF-19 might be reduced palmitate induced triglyceride accumulation and apoptosis (44).

\section{Ceramide Formation}

Exposure to excess long-chain saturated FFAs [palmitate (16:0), stearate (C18:0), arachidate (C20:0)] and linocerate (C24:0), but not shorter saturated [myristate (C12:0)] or unsaturated FFAs induces ceramide accumulation by serine palmitoyl transferase and ceramide synthase (CerS) $(45,46)$. de novo ceramide synthesis has been suggested to be a mediator of FFA-induced beta-cell toxicity. Overexpression of CerS4 potentiates PAinduced accumulation of ceramides and enhances apoptosis through the production of additional toxic ceramide species such as C18:0, C22:0, and C24:1 (47). The C2-ceramide, an analog of ceramide, is able to potentiate the pro-apoptosis and antiproliferative effects of PA in beta-cells (48). ER stress, alterations in mitochondrial membrane integrity, and inhibition of Akt by ceramide are proposed to induce apoptosis in beta-cells. Synthetic ceramide is accumulated in the ER of beta cells and reduces ER sphingomyelin (SM) and cholesterol, which results in the disruption of ER lipid rafts (49). Lei et al. demonstrated that inhibition of SMase, an enzyme that hydrolyzed SM to generate ceramide, protects beta-cells from ER stressinduced apoptosis (50). Also, ceramide increases mitochondrial membrane permeability and leads to the activation of intrinsic pathways via decreased anti-apoptotic molecules Bcl-2 and increased caspase 3/7 (47). Ceramide has been shown to disrupt electron transport at complex I and complex III, resulting in enhanced ROS generation, which facilitates cytochrome c release and caspase activation (51). Akt inactivation by ceramide is involved in the mechanisms by which ceramide causes betacell apoptosis. Inhibition of ceramide biosynthesis restores Akt activation (52), and Akt inactivation with ceramide accumulation is observed in human treated with saturated fat (53).

Inhibition of de novo ceramide synthesis by using serine palmitoyl transferase (L-cycloserine) or ceramide synthase (fumonisin-B1) inhibitors attenuates FFA-induced beta-cell apoptosis and lowers hyperglycemia (54). Tang et al. reported that beta-cell-secreted active neutral ceramidase protects beta cells from FFA-induced apoptosis through regulation of sphingolipid metabolites (55).

As ceramide and its derivatives have a variety of roles in beta-cell biology, further investigation will help to elucidate the mechanisms underlying beta-cell failure caused by lipotoxicity. 


\section{Lipid Droplet Formation}

Lipid droplets (LDs) is one of the important organelles in cellular energy balance. LD contains a core or neutral lipid (triglyceride (TG) and cholesterol ester) coated by an interface composed of a monolayer of phospholipids, free cholesterol and proteins (56). The storage droplets help transport the neutral lipids to specific cellular destinations or direct them to specific metabolic pathway. Such metabolic pathway was controlled by the LD coat proteins of the perilipin family such as perilipin (PLIN), adipocyte differentiation-related protein (ADFP), tail-interacting protein of 47 kilodaltons (TIP47) and oxidative tissue-enriched PAT protein (OXPAT) (57). PLIN protects against lipotoxicity when overexpressed beta-cells (58), but recently reported that that downregulation of PLIN2 ameliorates chemical induced ER stress (59). Identifying the role of PLIN on the lipotoxic beta-cells will be elucidated in the future. Besides PLIN, ADFP also plays a crucial function in intracellular lipid metabolism. Expression level of ADFP was increased in mouse islets from HFD administration and downregulation of ADFP in beta-cells results in the suppression of TG accumulation upon FA loading (60). However, few studies focused on the association of ADFP and beta-cell function under lipid stress. Further studies of PLIN and ADFP to increase understanding of lipid droplet formation in lipotoxic beta-cells will be needed.

\section{ER Stress}

The ER is one of the important metabolic organelles playing a key role in beta-cell function. Activation of ER plays a crucial role in the synthesis, correct folding and sorting of insulin in response to glucose. ER forms the main intracellular $\mathrm{Ca}^{2+}$ reservoir and the controlled release of $\mathrm{Ca}^{2+}$ into the cytosol is a critical step for insulin synthesis. Therefore, beta-cells are particularly sensitive to ER stress and unfolded protein response (UPR) such as ER transmembrane proteins PKR-like endoplasmic reticulum kinase (PERK), inositol-requiring enzyme (IRE)-1, and activating transcription factor (ATF)-6. Saturated FAs promote ER stress and induce beta-cell apoptosis $(61,62)$. ER stress markers are elevated in pancreatic islets in animal models of diabetes and in patients with type 2 diabetes (63). Chemical chaperone 4phenylbuturic acid treatment restores ER morphological changes induced by PA (64), and deletion of C/EBP homologous protein (CHOP, transcription factor in the ER stress response) in HFDfed mice improves beta-cell function and promotes cell survival (65).

Many pathways were involved in the regulation of ER stress induced apoptosis. Activated UPR pathways have been directly linked to the intrinsic apoptotic pathway (62). Proapoptotic signals of c-Jun N-terminal kinase (JNK), induced by PA, are activated downstream of IRE-1. Eukaryotic translation initiation factor 2 alpha subunit (eIF-2 $\alpha$ ) phosphorylation via PERK leads to loss of the myeloid cell leukemia sequence 1 (MCL1) protein, which is an anti-apoptotic member of the $\mathrm{BH} 3$ family (66). In addition, PA-induced ER stress interacted with the inflammatory response by activating several proinflammatory pathway, such as NF-kB, JNK, double stranded RNA-dependent protein kinase and nucleotide-binding oligomerization domain NLRP inflammasome (67).
Disruption of protein processing and trafficking or incorrect $\mathrm{Ca}^{2+}$ regulation in ER are involved in FA-induced beta-cell apoptosis. Compared with cytokines and glucotoxicity, PA efficiently decreased ER $\mathrm{Ca}^{2+}$ levels (68), and reduced $\mathrm{Ca}^{2+}$ levels in ER triggers the unfolded protein response to rescue cells from misfolded protein overload or programmed cell death (68). Marnugi et al. reported that Sorcin, a calcium sensor protein in ER, is downregulated under lipotoxic stress conditions, and resulting in ER stress and beta-cell dysfunction (69). Santulli et al. demonstrated that mutation of type 2 ryanodine receptor (RyR2), $\mathrm{Ca}^{2+}$ release channel on the ER, caused activated ER stress response, mitochondrial dysfunction and results in impaired insulin secretion and glucose homeostasis (70). The accumulation of misfolded protein causes ROS generation from the oxidative folding process in the ER and mitochondria. Defective disulfide bond formation reduces glutathione in the ER and produces oxygen radicals (71). Lipotoxicity also disrupts ER-to-Golgi protein trafficking, resulting in impaired proinsulin maturation and loss of insulin content (72).

The UPR causes accumulation of human islet amyloid polypeptide, which occurs in $90 \%$ of type 2 diabetic patients (73). Many studies have demonstrated that islet amyloid polypeptide formation is cytotoxic $(74,75)$ because amyloid polypeptide accumulates intracellular ROS and induces lipid peroxidation (74).

There are close connections between oxidative stress and organellar $\mathrm{Ca}^{2+}$ homeostasis. Interaction between $\mathrm{ER}$ and mitochondria was involved in the lipotoxicity- induced ER stress via regulation of $\mathrm{Ca}^{2+}$ signaling (76). Prolonged ER stress leads to release of $\mathrm{Ca}^{2+}$ from the ER lumen at the mitochondria-associated membranes (NAM) and consequently leads to increased $\mathrm{Ca}^{2+}$ uptake into the mitochondrial matrix. Prolonged mitochondrial $\mathrm{Ca}^{2+}$ accumulation triggers opening of the mitochondrial permeability transition pore (mtPTP) and these results in swelling the organelle, rupture of the outer mitochondrial membrane and release of proapoptotic protein into the cytosol (77). Ly et al. also suggested that palmitate induced deprivation of $\mathrm{Ca}^{2+}$ from ER and this leads to ER stress and $\mathrm{CHOP}$ upregulation. Moreover, released $\mathrm{Ca}^{2+}$ transfers into mitochondria and mitochondrial $\mathrm{Ca}^{2+}$ overload causes superoxide production and induces apoptosis (78).

These results suggest that several mechanisms are involved in lipotoxicity-induced ER stress. Therefore, reducing ER stress in beta- cells could lead to novel and efficient therapeutic treatments for palmitate-induced lipotoxicity. Several studies have demonstrated that knockdown of ER stress proteins (ex, $\mathrm{CHOP}$ ) has protective effects on palmitate-induced apoptosis in beta cells (79), and chaperones such as taurine-conjugated ursodeoxycholic acid (TUDCA) and 4-phenylbutyruc acids have been tested to protect from PA-induced ER stress and apoptosis (80).

\section{Mitochondrial Dysfunction}

Mitochondria play an essential role in adenosine triphosphate (ATP) synthesis, $\mathrm{Ca}^{2+}$ homeostasis, and the integration of apoptotic signals (81). In beta-cells, glucose sensing and subsequent insulin secretion was controlled by mitochondrial 
metabolism. During the glycolysis and tricarboxylic acid (TCA) cycle, reduced form of nicotinamide adenine dinucleotide $(\mathrm{NADH})$ or flavin adenine dinucleotide $(\mathrm{FADH} 2)$ are generated and electron transfer to the mitochondrial electron-transport chain (ETC) leads to production of ATP via the process of oxidative phosphorylation. Increased in ATP/ADP ratio allows $\mathrm{Ca}^{2+}$ uptake, contributing to secretion of insulin (82). Therefore, defects in mitochondrial function impair this metabolic process and consequently promote apoptosis and beta-cell death. Various factors have been identified that may contribute to mitochondrial dysfunction.

Increased FA levels leads to incomplete FA oxidation and induces ROS production, with concomitant mitochondrial stress, which leads to lipotoxicity (83). PA is known as a potent inducer of ROS and ROS attack insulin secreting cells and these results in mitochondrial inactivation and interruption of signal transduction correlated with insulin secretion (84). CD 36 is required for FA-induced ROS production and proinflammatory pathways (7).

Mitochondrial electron transport chain is an important site of ROS production within the cells, but beta-cells are low in antioxidant enzymes such as catalase, glutathione peroxidase, and superoxide dismutase, thus they are sensitive to ROS (85). Human islets from diabetic individuals show lipid peroxide protein adducts (86) and lipid infusion increases islet ROS and impairs insulin secretion (87). These lipid peroxides have lipotoxic effects on mtDNA, RNA and proteins of the mitochondrial machinery, leading to mitochondrial dysfunction (88).

Mitochondrial uncoupling refers to the dissociation of electron-dependent oxygen consumption from ATP generation. Uncoupling protein (UCP)-1,-2, and -3 are expressed in a tissue-specific manner, but only UCP-2 is expressed in pancreatic beta cells (89). Increased expression of UCP-2 is observed in islets of HFD-fed rodents and in FFA-treated islets (90), and activation of UCP-2 attenuates GSIS. Islets from UCP-2 KO mice show resistant to PA-induced cellular toxicity and remains normal insulin secretion (91). However, another report demonstrated that UCP-2 KO in mice causes oxidative stress and impairs GSIS (92). Recently, it was reported that UCP-2 is not involved in PAinduced impairment of insulin secretion in INS-1 cells (93). As there are contrasting results on the biochemical and physiological functions of UCP-2, further clarification of the role of UCP-2 in the lipotoxicity of beta-cells and the pathogenesis of diabetes is needed.

Mitochondrial morphology contributes to the maintenance of insulin levels by regulating apoptosis and beta-cell mass. Exposure of beta-cells to glucolipotoxicity induces mitochondrial fragmentation and restoring normal morphology prevents apoptosis (94). Mitochondria dynamics are modified by fission and fusion, as fusion can compensate for damage to the contents of dysfunctional organelles by fusing them with functionally competent ones, whereas fission drives damaged organelles to mitophagy and prevent apoptosis (95). It was reported that betacell specific deletion of autophagy related 7 (Atg-7) results in dispersed, small, and swollen mitochondria and accompanied by reduced beta-cell mass with reduced GSIS (96). It was reported that disconnected, swollen and shorter beta-cell mitochondria was observed in Zucker diabetic fatty rats (ZDF) (97) and beta-cells from diabetic patients (98). Molina et al. reported that PA treatment results in mitochondrial fragmentation and impairs network dynamics; moreover, manipulations that shift to fusion prevent lipotoxicity-induced apoptosis (99). In addition, Wiederkehr et al. demonstrated that inhibition of mitochondrial networking augments sensitivity to lipotoxicity (100). These results indicated that mitochondrial morphodynamics such as fusion and fission are involved in lipotoxicity in beta-cells and in the pathophysiology of type 2 diabetes.

Further elucidation of mitochondrial dysfunction and identification of mitochondrial targets against lipotoxicity will be helpful in identifying pharmacological targets for the protection of beta-cell mass and beta-cell function in type 2 diabetic subjects.

\section{Autophagy}

Autophagy is a dynamic process that has a major role in the elimination of pathogens, dysfunctional organelles, and protein aggregates through lysosomal mechanisms. Upon induction of stress such as ROS exposure or ER stress, autophagy is stimulated to protect the cell by clearing accumulated damaged components. The activating complex UNC-51-like kinase (ULK1)/ autophagyrelated protein (ATG)1, the Beclin/PI3K (VPS34) complex, two transmembrane proteins (ATG9 and VMPL), two ubiquitinlike conjugation systems (ATG12/ATG5 and ATG8/LC3) are molecular components involved in the autophagy process (101). Under normal condition, autophagy is inhibited by the activation of the mTORC1 complex, a modulator activated during the insulin pathway or in states of abundant nutrients. However, during energy reduction or in the presence of mTOR inhibitors, ATG proteins recruited to form a autophagy complex (102).

The role of autophagy in FFA-induced toxicity is unclear. When appropriate stimulation occurs, autophagy is activated as a survival mechanism (103). Numbers of autophagosomes are high in ZDF rats, db/db mice, and HFD-fed C57BL/6 mice (104). Long term treatment with PA or oleate to INS-1 cells show increased autophagosome numbers, and activation of autophagosomes indicates their protective role against PA-induced death (105, 106). Mice with a beta-cell-specific KO of ATG7 display impaired glucose tolerance as well as impaired insulin secretion after being fed a HFD (105), and reduction of autophagosome formation augments PA-induced beta-cell death (107). Choi et al also demonstrated that ATG5 downregulation enhanced susceptibility to cell death induced by lipotoxicity but stimulation of autophagy using rapamycin ameliorated lipotoxicity (106). These results suggested that increase autophagy in response to FA plays a protective mechanism from lipotoxicity.

In contrast, activation of autophagy by FAs in betacells has been reported to be an apoptotic signal. ATG7 overexpression sensitizes cells to PA-induced autophagy, which increases inflammatory mediators via cathepsin B and NLRP3 inflammasome, resulting in exacerbation of lipotoxicity in INS1 cells (108). Ebato et al. also reported that genetic deletion of ATG7 in beta-cells results in degeneration of islets and impaired 
glucose tolerance with reduced insulin secretion during high fat diet (105).

These contrary results suggest that induction of autophagy has either detrimental or protective roles in beta cells; therefore, the role of autophagy in beta-cell failure in type 2 diabetes requires further investigation.

\section{CONCLUSION}

Beta-cell failure is a major risk factor at the onset and during progression of type 2 diabetes. FFAs have both positive and negative effects on beta-cell survival and insulin secretory functions. However, chronic PA treatment results in lipotoxicity and beta-cell dysfunction, consequently resulting in type 2 diabetes. Several FFARs that are specifically activated by FFAs, disturbances in lipid metabolism and intracellular pathways, including cellular stress responses such as oxidative stress, ER stress, autophagy, and ceramide/LD formation are involved in lipotoxicity-induced beta-cell death. This review helps to understand the molecular mechanisms of lipotoxicity-induced type 2 diabetes, and

\section{REFERENCES}

1. Paolisso G, Tataranni PA, Foley JE, Bogardus C, Howard BV, Ravussin E. A high concentration of fasting plasma non-esterified fatty acids is a risk factor for the development of NIDDM. Diabetologia (1995) 38:1213-7. doi: 10.1007/s001250050414

2. Charles MA, Eschwege E, Thibult N, Claude JR, Warnet JM, Rosselin GE, et al. The role of non-esterified fatty acids in the deterioration of glucose tolerance in Caucasian subjects: results of the Paris Prospective Study. Diabetologia (1997) 40:1101-6. doi: 10.1007/s001250050793

3. Sharma RB, Alonso LC. Lipotoxicity in the pancreatic $\beta$ cell: not just survival and function, but proliferation as well? Curr Diab Rep. (2014) 14:492. doi: 10.1007/s11892-014-0492-2

4. Cnop M, Welsh N, Jonas JC, Jorns A, Lenzen S, Eizirik DL. Mechanisms of pancreatic $\beta$-cell death in type 1 and type 2 diabetes: many differences, few similarities. Diabetes (2005) 54 (Suppl. 2):S97-107. doi: 10.2337/diabetes.54.suppl_2.S97

5. Oh YS. Mechanistic insights into pancreatic $\beta$-cell mass regulation by glucose and free fatty acids. Anat Cell Biol. (2015) 48:16-24. doi: $10.5115 / \mathrm{acb} .2015 .48 .1 .16$

6. Johnston LW, Harris SB, Retnakaran R, Giacca A, Liu Z, Bazinet RP, et al. Association of NEFA composition with insulin sensitivity and $\beta$ cell function in the Prospective Metabolism and Islet Cell Evaluation (PROMISE) cohort. Diabetologia (2018) 61:821-30. doi: 10.1007/s00125-017-4534-6

7. Palomer X, Pizarro-Delgado J, Barroso E, Vazquez-Carrera M. Palmitic and oleic acid: the yin and yang of fatty acids in type 2 diabetes mellitus. Trends Endocrinol Metab. (2018) 29:178-90. doi: 10.1016/j.tem.2017.11.009

8. Poudyal H, Panchal SK, Ward LC, Brown L. Effects of ALA, EPA and DHA in high-carbohydrate, high-fat diet-induced metabolic syndrome in rats. J Nutr Biochem. (2013) 24:1041-52. doi: 10.1016/j.jnutbio.2012.07.014

9. Newsholme P, Keane D, Welters HJ, Morgan NG. Life and death decisions of the pancreatic $\beta$-cell: the role of fatty acids. Clin Sci. (2007) 112:27-42. doi: $10.1042 / C S 20060115$

10. Keane DC, Takahashi HK, Dhayal S, Morgan NG, Curi R, Newsholme P. Arachidonic acid actions on functional integrity and attenuation of the negative effects of palmitic acid in a clonal pancreatic $\beta$-cell line. Clin Sci. (2011) 120:195-206. doi: 10.1042/CS20100282

11. Baynes HW, Mideksa S, Ambachew S. The role of polyunsaturated fatty acids (n-3 PUFAs) on the pancreatic $\beta$-cells and insulin action. Adipocyte (2018) 14:1-7. doi: 10.1080/21623945.2018.1443662. [Epub ahead of print]. identification of the molecular mechanisms related to FFAs that regulate beta-cell mass and function could provide guidance in the development of new therapeutic targets for diabetes.

\section{AUTHOR CONTRIBUTIONS}

E-YP, DB, and GB collected information. YO and H-SJ collected information and wrote the manuscript.

\section{FUNDING}

This study was supported by a grant (NRF2015R1D1A1A01058888, NRF-2018R1C1B6000998) from the Basic Science Research Program through the National Research Foundation of Korea (NRF) funded by the Ministry of Science, ICT \& Future Planning and by a grant from the Korea Health Technology R\&D Project through the Korea Health Industry Development Institute (KHIDI), funded by the Ministry of Health \& Welfare, Republic of Korea (grant number: HI14C1135).

12. Su D, Zhang N, He J, Qu S, Slusher S, Bottino R, et al. Angiopoietin1 production in islets improves islet engraftment and protects islets from cytokine-induced apoptosis. Diabetes (2007) 56:2274-83. doi: $10.2337 / \mathrm{db} 07-0371$

13. Wei D, Li J, Shen M, Jia W, Chen N, Chen T, et al. Cellular production of n-3 PUFAs and reduction of n-6-to-n-3 ratios in the pancreatic $\beta$-cells and islets enhance insulin secretion and confer protection against cytokine-induced cell death. Diabetes (2010) 59:471-8. doi: 10.2337/db09-0284

14. Acosta-Montano P, Garcia-Gonzalez V. Effects of dietary fatty acids in pancreatic $\beta$ cell metabolism, implications in homeostasis. Nutrients (2018) 10:E393. doi: 10.3390/nu10040393

15. Hagman DK, Hays LB, Parazzoli SD, Poitout V. Palmitate inhibits insulin gene expression by altering PDX-1 nuclear localization and reducing MafA expression in isolated rat islets of Langerhans. J Biol Chem. (2005) 280:32413-8. doi: 10.1074/jbc.M506000200

16. Shimabukuro M, Zhou YT, Levi M, Unger RH. Fatty acid-induced $\beta$ cell apoptosis: a link between obesity and diabetes. Proc Natl Acad Sci U S A. (1998) 95:2498-502. doi: 10.1073/pnas.95.5.2498

17. Briaud I, Kelpe CL, Johnson LM, Tran PO, Poitout V. Differential effects of hyperlipidemia on insulin secretion in islets of langerhans from hyperglycemic versus normoglycemic rats. Diabetes (2002) 51:662-8. doi: 10.2337/diabetes.51.3.662

18. Carpentier AC, Bourbonnais A, Frisch F, Giacca A, Lewis GF. Plasma nonesterified Fatty Acid intolerance and hyperglycemia are associated with intravenous lipid-induced impairment of insulin sensitivity and disposition index. J Clin Endocrinol Metab. (2010) 95:1256-64. doi: 10.1210/jc. 2009-1932

19. Moulle VS, Ghislain J, Poitout V. Nutrient regulation of pancreatic $\beta$-cell proliferation. Biochimie (2017) 143:10-7. doi: 10.1016/j.biochi.2017.09.017

20. Silverstein RL, Li W, Park YM, Rahaman SO. Mechanisms of cell signaling by the scavenger receptor CD36: implications in atherosclerosis and thrombosis. Trans Am Clin Climatol Assoc. (2010) 121:206-20.

21. Wallin T, Ma Z, Ogata H, Jorgensen IH, Iezzi M, Wang H, et al. Facilitation of fatty acid uptake by CD36 in insulin-producing cells reduces fatty-acidinduced insulin secretion and glucose regulation of fatty acid oxidation. Biochim Biophys Acta (2010) 1801:191-7. doi: 10.1016/j.bbalip.2009. 11.002

22. Hua W, Huang HZ, Tan LT, Wan JM, Gui HB, Zhao L, et al. CD36 Mediated fatty acid-induced podocyte apoptosis via oxidative stress. PLoS ONE (2015) 10:e127507. doi: 10.1371/journal.pone.0127507 
23. Vangaveti V, Shashidhar V, Jarrod G, Baune BT, Kennedy RL. Free fatty acid receptors: emerging targets for treatment of diabetes and its complications. Ther Adv Endocrinol Metab. (2010) 1:165-75. doi: $10.1177 / 2042018810381066$

24. Itoh Y, Kawamata Y, Harada M, Kobayashi M, Fujii R, Fukusumi S, et al. Free fatty acids regulate insulin secretion from pancreatic $\beta$ cells through GPR40. Nature (2003) 422:173-6. doi: 10.1038/nature01478

25. Miyauchi S, Hirasawa A, Ichimura A, Hara T, Tsujimoto G. New frontiers in gut nutrient sensor research: free fatty acid sensing in the gastrointestinal tract. J Pharmacol Sci. (2010) 112:19-24. doi: 10.1254/jphs.09R09FM

26. Steneberg P, Rubins N, Bartoov-Shifman R, Walker MD, Edlund H. The FFA receptor GPR40 links hyperinsulinemia, hepatic steatosis, and impaired glucose homeostasis in mouse. Cell Metab. (2005) 1:245-58. doi: 10.1016/j.cmet.2005.03.007

27. Kristinsson H, Smith DM, Bergsten P, Sargsyan E. FFAR1 is involved in both the acute and chronic effects of palmitate on insulin secretion. Endocrinology (2013) 154:4078-88. doi: 10.1210/en.2013-1352

28. Tuo Y, Feng DD, Wang DF, Sun J, Li SB, Chen C. Long-term in vitro treatment of INS-1 rat pancreatic $\beta$-cells by unsaturated free fatty acids protects cells against gluco- and lipotoxicities via activation of GPR40 receptors. Clin Exp Pharmacol Physiol. (2012) 39:423-8. doi: 10.1111/j.1440-1681.2012.05691.x

29. Nagasumi K, Esaki R, Iwachidow K, Yasuhara Y, Ogi K, Tanaka H, et al. Overexpression of GPR40 in pancreatic $\beta$-cells augments glucose-stimulated insulin secretion and improves glucose tolerance in normal and diabetic mice. Diabetes (2009) 58:1067-76. doi: 10.2337/db08-1233

30. Wagner R, Kaiser G, Gerst F, Christiansen E, Due-Hansen ME, Grundmann $\mathrm{M}$, et al. Reevaluation of fatty acid receptor 1 as a drug target for the stimulation of insulin secretion in humans. Diabetes (2013) 62:2106-11. doi: $10.2337 / \mathrm{db} 12-1249$

31. Liou AP, Lu X, Sei Y, Zhao X, Pechhold S, Carrero RJ, et al. The Gprotein-coupled receptor GPR40 directly mediates long-chain fatty acidinduced secretion of cholecystokinin. Gastroenterology (2011) 140:903-12. doi: 10.1053/j.gastro.2010.10.012

32. Li Z, Xu X, Huang W, Qian H. Free Fatty Acid Receptor 1 (FFAR1) as an emerging therapeutic target for type 2 diabetes mellitus: recent progress and prevailing challenges. Med Res Rev (2018) 38:381-425. doi: 10.1002/med.21441

33. Leifke E, Naik H, Wu J, Viswanathan P, Demanno D, Kipnes M, et al. A multiple-ascending-dose study to evaluate safety, pharmacokinetics, and pharmacodynamics of a novel GPR40 agonist, TAK-875, in subjects with type 2 diabetes. Clin Pharmacol Ther. (2012) 92:29-39. doi: 10.1038/clpt. 2012.43

34. Li X, Zhong K, Guo Z, Zhong D, Chen X. Fasiglifam (TAK-875) Inhibits hepatobiliary transporters: a possible factor contributing to Fasiglifam-induced liver injury. Drug Metab Dispos. (2015) 43:1751-9. doi: $10.1124 / \mathrm{dmd} .115 .064121$

35. Hirasawa A, Tsumaya K, Awaji T, Katsuma S, Adachi T, Yamada M, et al. Free fatty acids regulate gut incretin glucagon-like peptide-1 secretion through GPR120. Nat Med. (2005) 11:90-4. doi: 10.1038/nm1168

36. Katsuma S, Hatae N, Yano T, Ruike Y, Kimura M, Hirasawa A, et al. Free fatty acids inhibit serum deprivation-induced apoptosis through GPR120 in a murine enteroendocrine cell line STC-1. J Biol Chem. (2005) 280:19507-15. doi: 10.1074/jbc.M412385200

37. Ichimura A, Hirasawa A, Poulain-Godefroy O, Bonnefond A, Hara T, Yengo L, et al. Dysfunction of lipid sensor GPR120 leads to obesity in both mouse and human. Nature (2012) 483:350-4. doi: 10.1038/nature10798

38. Tang C, Ahmed K, Gille A, Lu S, Grone HJ, Tunaru S, et al. Loss of FFA2 and FFA3 increases insulin secretion and improves glucose tolerance in type 2 diabetes. Nat Med. (2015) 21:173-7. doi: 10.1038/nm.3779

39. Tolhurst G, Heffron H, Lam YS, Parker HE, Habib AM, Diakogiannaki E, et al. Short-chain fatty acids stimulate glucagon-like peptide-1 secretion via the G-protein-coupled receptor FFAR2. Diabetes (2012) 61:364-71. doi: $10.2337 / \mathrm{db} 11-1019$

40. Chu ZL, Jones RM, He H, Carroll C, Gutierrez V, Lucman A, et al. A role for $\beta$-cell-expressed $G$ protein-coupled receptor 119 in glycemic control by enhancing glucose-dependent insulin release. Endocrinology (2007) 148:2601-9. doi: 10.1210/en.2006-1608
41. Chu ZL, Carroll C, Chen R, Alfonso J, Gutierrez V, He H, et al. Noleoyldopamine enhances glucose homeostasis through the activation of GPR119. Mol Endocrinol. (2010) 24:161-70. doi: 10.1210/me.2009-0239

42. Grygiel-Gorniak B. Peroxisome proliferator-activated receptors and their ligands: nutritional and clinical implications-a review. Nutr J. (2014) 13:17. doi: 10.1186/1475-2891-13-17

43. Frigerio F, Brun T, Bartley C, Usardi A, Bosco D, Ravnskjaer K, et al. Peroxisome proliferator-activated receptor alpha (PPARalpha) protects against oleate-induced INS-1E $\beta$ cell dysfunction by preserving carbohydrate metabolism. Diabetologia (2010) 53:331-40. doi: 10.1007/s00125-009-1590-6

44. Popescu IR, Helleboid-Chapman A, Lucas A, Vandewalle B, Dumont J, Bouchaert $\mathrm{E}$, et al. The nuclear receptor FXR is expressed in pancreatic $\beta$-cells and protects human islets from lipotoxicity. FEBS Lett. (2010) 584:2845-51. doi: 10.1016/j.febslet.2010.04.068

45. Chavez JA, Summers SA. Characterizing the effects of saturated fatty acids on insulin signaling and ceramide and diacylglycerol accumulation in 3T3-L1 adipocytes and C2C12 myotubes. Arch Biochem Biophys (2003) 419:101-9. doi: 10.1016/j.abb.2003.08.020

46. Summers SA. Ceramides in insulin resistance and lipotoxicity. Prog Lipid Res. (2006) 45:42-72. doi: 10.1016/j.plipres.2005.11.002

47. Veret J, Coant N, Berdyshev EV, Skobeleva A, Therville N, Bailbe D, et al. Ceramide synthase 4 and de novo production of ceramides with specific $\mathrm{N}$-acyl chain lengths are involved in glucolipotoxicity-induced apoptosis of INS-1 $\beta$-cells. Biochem J. (2011) 438:177-89. doi: 10.1042/BJ20101386

48. Maedler K, Oberholzer J, Bucher P, Spinas GA, Donath MY. Monounsaturated fatty acids prevent the deleterious effects of palmitate and high glucose on human pancreatic $\beta$-cell turnover and function. Diabetes (2003) 52:726-33. doi: 10.2337/diabetes.52.3.726

49. Boslem E, Weir JM, MacIntosh G, Sue N, Cantley J, Meikle PJ, et al. Alteration of endoplasmic reticulum lipid rafts contributes to lipotoxicity in pancreatic $\beta$-cells. J Biol Chem. (2013) 288:26569-82. doi: 10.1074/jbc.M113.489310

50. Lei X, Zhang S, Emani B, Barbour SE, Ramanadham S. A link between endoplasmic reticulum stress-induced $\beta$-cell apoptosis and the group VIA $\mathrm{Ca}^{2+}$-independent phospholipase $\mathrm{A}_{2}\left(\mathrm{iPLA}_{2} \beta\right)$. Diabetes Obes Metab. (2010) 12(Suppl. 2):93-8. doi: 10.1111/j.1463-1326.2010.01270.x

51. Garcia-Ruiz C, Colell A, Morales A, Calvo M, Enrich C, Fernandez-Checa JC. Trafficking of ganglioside GD3 to mitochondria by tumor necrosis factor-alpha. J Biol Chem. (2002) 277:36443-8. doi: 10.1074/jbc.M206021200

52. Chavez JA, Knotts TA, Wang LP, Li G, Dobrowsky RT, Florant GL, et al. A role for ceramide, but not diacylglycerol, in the antagonism of insulin signal transduction by saturated fatty acids. J Biol Chem. (2003) 278:10297-303. doi: 10.1074/jbc.M212307200

53. Bachmann OP, Dahl DB, Brechtel K, Machann J, Haap M, Maier T, et al. Effects of intravenous and dietary lipid challenge on intramyocellular lipid content and the relation with insulin sensitivity in humans. Diabetes (2001) 50:2579-84. doi: 10.2337/diabetes.50.11.2579

54. Shimabukuro M, Higa M, Zhou YT, Wang MY, Newgard CB, Unger RH. Lipoapoptosis in $\beta$-cells of obese prediabetic fa/fa rats. Role of serine palmitoyltransferase overexpression. J Biol Chem. (1998) 273:32487-90. doi: $10.1074 /$ jbc.273.49.32487

55. Tang S, Luo F, Feng YM, Wei X, Miao H, Lu YB, et al. Neutral ceramidase secreted via exosome protects against palmitate-induced apoptosis in INS-1 cells. Exp Clin Endocrinol Diabetes (2017) 125:130-5. doi: $10.1055 / \mathrm{s}-0042-116314$

56. Ducharme NA, Bickel PE. Lipid droplets in lipogenesis and lipolysis. Endocrinology (2008) 149:942-9. doi: 10.1210/en.2007-1713

57. Brasaemle DL. Thematic review series: adipocyte biology. The perilipin family of structural lipid droplet proteins: stabilization of lipid droplets and control of lipolysis. J Lipid Res. (2007) 48:2547-59. doi: 10.1194/jlr.R700014-JLR200

58. Borg J, Klint C, Wierup N, Strom K, Larsson S, Sundler F, et al. Perilipin is present in islets of Langerhans and protects against lipotoxicity when overexpressed in the $\beta$-cell line INS-1. Endocrinology (2009) 150:3049-57. doi: 10.1210/en.2008-0913

59. Chen E, Tsai TH, Li L, Saha P, Chan L, Chang BH. PLIN2 is a key regulator of the unfolded protein response and endoplasmic reticulum stress resolution in pancreatic $\beta$ cells. Sci Rep. (2017) 7:40855. doi: 10.1038/srep40855 
60. Faleck DM, Ali K, Roat R, Graham MJ, Crooke RM, Battisti R, et al. Adipose differentiation-related protein regulates lipids and insulin in pancreatic islets. Am J Physiol Endocrinol Metab. (2010) 299:E249-57. doi: 10.1152/ajpendo.00646.2009

61. Laybutt DR, Preston AM, Akerfeldt MC, Kench JG, Busch AK, Biankin AV, et al. Endoplasmic reticulum stress contributes to $\beta$ cell apoptosis in type 2 diabetes. Diabetologia (2007) 50:752-63. doi: 10.1007/s00125-006-0590-Z

62. Biden TJ, Boslem E, Chu KY, Sue N. Lipotoxic endoplasmic reticulum stress, $\beta$ cell failure, and type 2 diabetes mellitus. Trends Endocrinol Metab. (2014) 25:389-98. doi: 10.1016/j.tem.2014.02.003

63. Marchetti P, Bugliani M, Lupi R, Marselli L, Masini M, Boggi U, et al. The endoplasmic reticulum in pancreatic $\beta$ cells of type 2 diabetes patients. Diabetologia (2007) 50:2486-94. doi: 10.1007/s00125-007-0816-8

64. Choi SE, Lee YJ, Jang HJ, Lee KW, Kim YS, Jun HS, et al. A chemical chaperone 4-PBA ameliorates palmitate-induced inhibition of glucosestimulated insulin secretion (GSIS). Arch Biochem Biophys. (2008) 475:10914. doi: 10.1016/j.abb.2008.04.015

65. Song B, Scheuner D, Ron D, Pennathur S, Kaufman RJ. Chop deletion reduces oxidative stress, improves $\beta$ cell function, and promotes cell survival in multiple mouse models of diabetes. J Clin Invest. (2008) 118:3378-89. doi: 10.1172/JCI34587

66. Allagnat F, Cunha D, Moore F, Vanderwinden JM, Eizirik DL, Cardozo AK. Mcl-1 downregulation by pro-inflammatory cytokines and palmitate is an early event contributing to $\beta$-cell apoptosis. Cell Death Differ (2011) 18:328-37. doi: 10.1038/cdd.2010.105

67. Salvado L, Palomer X, Barroso E, Vazquez-Carrera M. Targeting endoplasmic reticulum stress in insulin resistance. Trends Endocrinol Metab. (2015) 26:438-48. doi: 10.1016/j.tem.2015.05.007

68. Hara T, Mahadevan J, Kanekura K, Hara M, Lu S, Urano F. Calcium efflux from the endoplasmic reticulum leads to $\beta$-cell death. Endocrinology (2014) 155:758-68. doi: 10.1210/en.2013-1519

69. Marmugi A, Parnis J, Chen X, Carmichael L, Hardy J, Mannan N, et al. Sorcin Links Pancreatic $\beta$-Cell Lipotoxicity to ER $\mathrm{Ca}^{2+}$ Stores. Diabetes (2016) 65:1009-21. doi: 10.2337/db15-1334

70. Santulli G, Pagano G, Sardu C, Xie W, Reiken S, D’Ascia SL, et al. Calcium release channel RyR2 regulates insulin release and glucose homeostasis. JClin Invest. (2015) 125:1968-78. doi: 10.1172/JCI79273

71. Haynes CM, Titus EA, Cooper AA. Degradation of misfolded proteins prevents ER-derived oxidative stress and cell death. Mol Cell. (2004) 15:76776. doi: 10.1016/j.molcel.2004.08.025

72. Preston AM, Gurisik E, Bartley C, Laybutt DR, Biden TJ. Reduced endoplasmic reticulum (ER)-to-Golgi protein trafficking contributes to ER stress in lipotoxic mouse $\beta$ cells by promoting protein overload. Diabetologia (2009) 52:2369-73. doi: 10.1007/s00125-009-1506-5

73. Cadavez L, Montane J, Alcarraz-Vizan G, Visa M, Vidal-Fabrega L, Servitja $\mathrm{JM}$, et al. Chaperones ameliorate $\beta$ cell dysfunction associated with human islet amyloid polypeptide overexpression. PLoS ONE (2014) 9:e101797. doi: 10.1371/journal.pone.0101797

74. Konarkowska B, Aitken JF, Kistler J, Zhang S, Cooper GJ. The aggregation potential of human amylin determines its cytotoxicity towards islet $\beta$-cells. FEBS J. (2006) 273:3614-24. doi: 10.1111/j.1742-4658.2006.05367.x

75. Meier JJ, Kayed R, Lin CY, Gurlo T, Haataja L, Jayasinghe S, et al. Inhibition of human IAPP fibril formation does not prevent $\beta$-cell death: evidence for distinct actions of oligomers and fibrils of human IAPP. Am J Physiol Endocrinol Metab. (2006) 291:E1317-24. doi: 10.1152/ajpendo.00082.2006

76. Szabadkai G, Duchen MR. Mitochondria: the hub of cellular $\mathrm{Ca}^{2+}$ signaling. Physiology (2008) 23:84-94. doi: 10.1152/physiol.00046.2007

77. Deniaud A, Sharaf el dein O, Maillier E, Poncet D, Kroemer G, Lemaire C, et al. Endoplasmic reticulum stress induces calcium-dependent permeability transition, mitochondrial outer membrane permeabilization and apoptosis. Oncogene (2008) 27:285-99. doi: 10.1038/sj.onc. 1210638

78. Ly LD, Xu S, Choi SK, Ha CM, Thoudam T, Cha SK, et al. Oxidative stress and calcium dysregulation by palmitate in type 2 diabetes. Exp Mol Med. (2017) 49:e291. doi: 10.1038/emm.2016.157

79. Cunha DA, Hekerman P, Ladriere L, Bazarra-Castro A, Ortis F, Wakeham $\mathrm{MC}$, et al. Initiation and execution of lipotoxic ER stress in pancreatic $\beta$-cells. J Cell Sci. (2008) 121:2308-18. doi: 10.1242/jcs.026062
80. Pfaffenbach KT, Gentile CL, Nivala AM, Wang D, Wei Y, Pagliassotti MJ. Linking endoplasmic reticulum stress to cell death in hepatocytes: roles of C/EBP homologous protein and chemical chaperones in palmitatemediated cell death. Am J Physiol Endocrinol Metab. (2010) 298:E1027-35. doi: 10.1152/ajpendo.00642.2009

81. Wiederkehr A, Wollheim CB. Minireview: implication of mitochondria in insulin secretion and action. Endocrinology (2006) 147:2643-9. doi: 10.1210/en.2006-0057

82. Wiederkehr A, Wollheim CB. Mitochondrial signals drive insulin secretion in the pancreatic $\beta$-cell. Mol Cell Endocrinol. (2012) 353:128-37. doi: 10.1016/j.mce.2011.07.016

83. Tumova J, Andel M, Trnka J. Excess of free fatty acids as a cause of metabolic dysfunction in skeletal muscle. Physiol Res. (2016) 65:193-207.

84. Maechler P, Jornot L, Wollheim CB. Hydrogen peroxide alters mitochondrial activation and insulin secretion in pancreatic $\beta$ cells. J Biol Chem. (1999) 274:27905-13. doi: 10.1074/jbc.274.39.27905

85. Tiedge M, Lortz S, Drinkgern J, Lenzen S. Relation between antioxidant enzyme gene expression and antioxidative defense status of insulinproducing cells. Diabetes (1997) 46:1733-42. doi: 10.2337/diab.46.11.1733

86. MacDonald MJ, Langberg EC, Tibell A, Sabat G, Kendrick MA, Szweda LI, et al. Identification of ATP synthase as a lipid peroxide protein adduct in pancreatic islets from humans with and without type 2 diabetes mellitus. J Clin Endocrinol Metab. (2013) 98:E727-31. doi: 10.1210/jc. 2012-4203

87. Carlsson C, Borg LA, Welsh N. Sodium palmitate induces partial mitochondrial uncoupling and reactive oxygen species in rat pancreatic islets in vitro. Endocrinology (1999) 140:3422-8. doi: 10.1210/endo.140.8. 6908

88. Supale S, Li N, Brun T, Maechler P. Mitochondrial dysfunction in pancreatic $\beta$ cells. Trends Endocrinol Metab (2012) 23:477-87. doi: 10.1016/j.tem.2012.06.002

89. Chan CB, MacDonald PE, Saleh MC, Johns DC, Marban E, Wheeler MB. Overexpression of uncoupling protein 2 inhibits glucosestimulated insulin secretion from rat islets. Diabetes (1999) 48:1482-6. doi: 10.2337/diabetes.48.7.1482

90. Poitout V, Amyot J, Semache M, Zarrouki B, Hagman D, Fontes G. Glucolipotoxicity of the pancreatic $\beta$ cell. Biochim Biophys Acta (2010) 1801:289-98. doi: 10.1016/j.bbalip.2009.08.006

91. Joseph JW, Koshkin V, Saleh MC, Sivitz WI, Zhang CY, Lowell BB, et al. Free fatty acid-induced $\beta$-cell defects are dependent on uncoupling protein 2 expression. J Biol Chem. (2004) 279:51049-56. doi: 10.1074/jbc.M409189200

92. Pi J, Bai Y, Daniel KW, Liu D, Lyght O, Edelstein D, et al. Persistent oxidative stress due to absence of uncoupling protein 2 associated with impaired pancreatic $\beta$-cell function. Endocrinology (2009) 150:3040-8. doi: $10.1210 /$ en.2008-1642

93. Hirschberg Jensen V, Affourtit C. Mitochondrial uncoupling protein-2 is not involved in palmitate-induced impairment of glucose-stimulated insulin secretion in INS-1E insulinoma cells and is not needed for the amplification of insulin release. Biochem Biophys Rep. (2015) 1:8-15. doi: 10.1016/j.bbrep.2015.03.008

94. Higa M, Zhou YT, Ravazzola M, Baetens D, Orci L, Unger RH. Troglitazone prevents mitochondrial alterations, $\beta$ cell destruction, and diabetes in obese prediabetic rats. Proc Natl Acad Sci U S A. (1999) 96:11513-8. doi: $10.1073 /$ pnas.96.20.11513

95. Twig G, Elorza A, Molina AJ, Mohamed H, Wikstrom JD, Walzer G, et al. Fission and selective fusion govern mitochondrial segregation and elimination by autophagy. EMBO J. (2008) 27:433-46. doi: 10.1038/sj.emboj.7601963

96. Jung HS, Chung KW, Won Kim J, Kim J, Komatsu M, Tanaka K, et al. Loss of autophagy diminishes pancreatic $\beta$ cell mass and function with resultant hyperglycemia. Cell Metab. (2008) 8:318-24. doi: 10.1016/j.cmet.2008.08.013

97. Bindokas VP, Kuznetsov A, Sreenan S, Polonsky KS, Roe MW, Philipson LH. Visualizing superoxide production in normal and diabetic rat islets of Langerhans. J Biol Chem. (2003) 278:9796-801. doi: 10.1074/jbc.M206913200

98. Anello M, Lupi R, Spampinato D, Piro S, Masini M, Boggi U, et al. Functional and morphological alterations of mitochondria in pancreatic 
$\beta$ cells from type 2 diabetic patients. Diabetologia (2005) 48:282-9. doi: 10.1007/s00125-004-1627-9

99. Molina AJ, Wikstrom JD, Stiles L, Las G, Mohamed H, Elorza A, et al. Mitochondrial networking protects $\beta$-cells from nutrient-induced apoptosis. Diabetes (2009) 58:2303-15. doi: 10.2337/db07-1781

100. Wiederkehr A, Wollheim CB. Linking fatty acid stress to $\beta$-cell mitochondrial dynamics. Diabetes (2009) 58:2185-6. doi: 10.2337/db09-0967

101. Las G, Shirihai OS. The role of autophagy in $\beta$-cell lipotoxicity and type 2 diabetes. Diabetes Obes Metab. (2010) 12 (Suppl. 2):15-9. doi: 10.1111/j.1463-1326.2010.01268.x

102. Wong PM, Puente C, Ganley IG, Jiang X. The ULK1 complex: sensing nutrient signals for autophagy activation. Autophagy (2013) 9:124-37. doi: 10.4161/auto.23323

103. Parzych KR, Klionsky DJ. An overview of autophagy: morphology, mechanism, and regulation. Antioxid Redox Signal. (2014) 20:460-73. doi: 10.1089 /ars.2013.5371

104. Li X, Zhang L, Meshinchi S, Dias-Leme C, Raffin D, Johnson JD, et al. Islet microvasculature in islet hyperplasia and failure in a model of type 2 diabetes. Diabetes (2006) 55:2965-73. doi: 10.2337/db06-0733

105. Ebato C, Uchida T, Arakawa M, Komatsu M, Ueno T, Komiya K, et al. Autophagy is important in islet homeostasis and compensatory increase of $\beta$ cell mass in response to high-fat diet. Cell Metab. (2008) 8:325-32. doi: 10.1016/j.cmet.2008.08.009
106. Choi SE, Lee SM, Lee YJ, Li LJ, Lee SJ, Lee JH, et al. Protective role of autophagy in palmitate-induced INS-1 $\beta$-cell death. Endocrinology (2009) 150:126-34. doi: 10.1210/en.2008-0483

107. Las G, Serada SB, Wikstrom JD, Twig G, Shirihai OS. Fatty acids suppress autophagic turnover in $\beta$-cells. J Biol Chem. (2011) 286:42534-4. doi: 10.1074/jbc.M111.242412

108. Li S, Du L, Zhang L, Hu Y, Xia W, Wu J, et al. Cathepsin B contributes to autophagy-related 7 (Atg7)-induced nod-like receptor 3 (NLRP3)dependent proinflammatory response and aggravates lipotoxicity in rat insulinoma cell line. J Biol Chem. (2013) 288:30094-104. doi: 10.1074/jbc.M113.494286

Conflict of Interest Statement: The authors declare that the research was conducted in the absence of any commercial or financial relationships that could be construed as a potential conflict of interest.

Copyright (C) 2018 Oh, Bae, Baek, Park and Jun. This is an open-access article distributed under the terms of the Creative Commons Attribution License (CC BY). The use, distribution or reproduction in other forums is permitted, provided the original author(s) and the copyright owner(s) are credited and that the original publication in this journal is cited, in accordance with accepted academic practice. No use, distribution or reproduction is permitted which does not comply with these terms. 